\title{
Crystallization of Intact and Subunit L-Deficient Monomers from Synechocystis PCC 6803 Photosystem I
}

\author{
Petra Jekowa ${ }^{\mathrm{a}}$, Wolf-Dieter Schubert ${ }^{\mathrm{a}}$, Petra Fromme ${ }^{\mathrm{b}}$, Jochen Kruip ${ }^{\mathrm{c}}$, \\ Parag R. Chitnis ${ }^{\mathrm{d}}$, Matthias Rögner ${ }^{\mathrm{c}}$, and Wolfram Saenger ${ }^{\mathrm{a}}$ \\ a Institut für Kristallographie, Freie Universität Berlin, Takustraße 6, 14195 Berlin, \\ Bundesrepublik Deutschland \\ b Max-Volmer-Institut für Biophysikalische und Physikalische Chemie, \\ Technische Universität Berlin, Straße des 17. Juni 135, 10623 Berlin, \\ Bundesrepublik Deutschland \\ c Institut für Botanik, Universität Münster, Schloßgarten 3, 48149 Münster, \\ Bundesrepublik Deutschland \\ d Division of Biology, Kansas State University, Manhattan, Kansas 66506, USA \\ Z. Naturforsch. 51 c, 195-199 (1996); received October 24/December 13, 1995 \\ Photosystem I, PS I Monomers, Crystallization, Mesophilic Cyanobacterium
}

Photosystem I monomers from wildtype cells of Synechocystis PCC 6803 and from a mutant deficient in the psaL gene were crystallized. PsaL encodes for the hydrophobic subunit $\mathrm{L}$, which has been proposed to constitute the trimerization domain in the PS I trimer. The absence of subunit $\mathrm{L}$ facilitated crystallization of the PS I monomer. The unit cell dimensions and the space group for the crystals from this preparation could be determined to be $a=b=$ $132 \AA, c=525 \AA, \alpha=\beta=90^{\circ}, \gamma=120^{\circ}$, the space group is $\mathrm{P} 6_{1}$ or $\mathrm{P} 6_{5}$. The results show the potential of using specifically designed deletion mutants of an integral membrane protein for the systematic improvement of crystal structure data.

\section{Introduction}

The two photosystems I (PS I) and II (PS II) in the thylakoid membrane of cyanobacteria and plants are responsible for the light induced transmembrane charge separation in water splitting photosynthesis. PS I is an integral membrane protein complex, which catalyzes the light-induced transport of electrons across the membrane from either plastocyanin or cytochrome $c_{6}$ to ferredoxin or flavodoxin (Golbeck, 1993). Cyanobacterial PS I consists of at least 11 subunits, which are called A to $\mathrm{F}$ and $\mathrm{I}$ to $\mathrm{M}$ according to their encoding genes $p s a A$ to $p s a F$ and $p s a I$ to $p s a M$ (Mühlenhoff et al., 1993). The two major subunits A and B bind

Abbreviations: PS I, PS II, photosystems I and II; sulfobetaine 12, N,N-dimethyl-n-dodecylamino-3-propanesulfonate; $\beta$-DM, n-dodecyl- $\beta$-D-maltoside; Tris $/ \mathrm{HCl}$, tris(hydroxymethyl)-aminomethane $+\mathrm{HCl}$; $\mathrm{P} 700$, primary electron donor of photosystem I; PEG, polyethylene glycol; Mes/ $\mathrm{NaOH}, 2$-(N-morpholino)-ethane sulfonic acid $+\mathrm{NaOH} ;$ Hepes/NaOH, (N-[2-hydroxyethyl]piperazine$\mathrm{N}^{\prime}$-[2-ethane sulfonic acid]) $+\mathrm{NaOH}$; PS I $\{$-L\}, PS I $\{-\mathrm{K},-\mathrm{L}\}$, photosystem I deficient in subunit L or both subunits $\mathrm{K}$ and $\mathrm{L}$.

Reprint requests to W. Saenger. the primary electron donor P700 (a chlorophyll $a$ dimer), the primary and secondary electron acceptors $\mathrm{A}_{0}$ (chlorophyll $a$ ) and $\mathrm{A}_{1}$ (phylloquinone, vitamin $\mathrm{k}_{1}$ ) as well as the $[4 \mathrm{Fe} 4 \mathrm{~S}]$ cluster $\mathrm{F}_{\mathrm{X}}$. The two terminal [4Fe4S] clusters $\mathrm{F}_{\mathrm{A}}$ and $\mathrm{F}_{\mathrm{B}}$ are located within the stromal subunit $\mathrm{C}$. In addition, 90 to 100 chlorophyll $a$ molecules and 12 to $15 \beta$ carotenes are bound to subunits $\mathrm{A}$ and $\mathrm{B}$. The smaller subunits $\mathrm{D}$ to $\mathrm{F}$ and $\mathrm{I}$ to $\mathrm{M}$ are not known to contain any cofactors (Golbeck, 1993). The total molecular mass of the isolated monomeric protein complex is at least $340 \mathrm{kDa}$ (deduced from the code of the isolated genes (Mühlenhoff et al., 1993 ) and the content of chromophores).

Cyanobacterial PS I can be extracted from photosynthetic membranes in trimeric and monomeric form depending on conditions (Kruip et al., 1993), both forms have been prepared and characterized by several authors (Almog et al., 1991, Kruip et al., 1993 (2), Rögner et al., 1990 (1, 2), Ford and Holzenburg, 1988). The structure of the PS I trimer from Synechococcus elongatus has been determined at a resolution of $6 \AA$ by X-ray crystal structure analysis (Krauß et al., 1993). In this trimeric complex, each monomer consists of a larger catalytic domain and a smaller connecting domain; the 
latter is in close proximity to the threefold axis and connects the monomers into trimers. This connecting domain is presumed to contain subunit $\mathrm{L}$ (Chitnis and Chitnis, 1993, Jekow et al., 1995) and protrudes from the globular shape of the intact monomeric PS I molecule. It was proposed that this protrusion might be the reason that crystals of PS I monomers from Synechococcus elongatus deficient in subunits $\mathrm{K}$ and $\mathrm{L}$ are more easily grown than those of intact monomers containing all subunits (Jekow et al., 1995). In the former case, the subunits had been removed from the protein by treatment with the zwitterionic detergent SB12. More homogeneous preparations are expected from the mutant of the mesophilic cyanobacterium Synechocystis PCC 6803 where the psaL gene encoding for subunit $\mathrm{L}$ is missing (Chitnis et al., 1993). These cells are no longer able to form trimeric PS I in the thylakoid membrane and are still biologically active. The protein deficient in subunit $\mathrm{L}$ will henceforth be referred to as PS I $\{-\mathrm{L}\}$ as compared to the "intact PS I" monomer containing all subunits.

Here we show that by using complexes isolated from psaL-deletion mutants, the range of conditions yielding crystals from PS I monomers is significantly increased. The X-ray diffraction patterns of these crystals are improved in comparison to those from intact PS I monomer crystals from $S y$ nechocystis PCC 6803 to an extent that the unit cell dimensions and space group could be determined.

\section{Material and Methods}

Cells from wildtype Synechocystis PCC 6803 and from the subunit L-deficient mutant were grown and harvested as described (Rögner et al., 1990). They were extracted from the membrane and subsequently purified essentially as outlined in (Kruip et al., 1993). In the case of the wildtype cells, PS I can be extracted from the membrane of Synechocystis PCC 6803 in monomeric or trimeric form. The amount of extracted PS I monomers was increased to nearly $100 \%$ by using high ionic strength in the extraction buffer. The cells deficient in the PsaL gene were not able to form PS I trimers in the membrane. PS I from these mutants was therefore exclusively prepared in monomeric form.
For crystallization, the vapour diffusion technique in the hanging drop mode was used (Jekow et al., 1995). The protein preparations were adjusted to a final protein concentration of $10 \mathrm{mg} / \mathrm{ml}$ using buffer containing $20 \mathrm{~mm}$ Mes $\mathrm{pH}$ 6.4, $0.02 \%$ $(w / v) \beta$-DM. This solution was mixed with different precipitating solutions in a volume ratio of (1:2) according to the screening test designed by Jancarik and Kim, 1991, on the basis of the incomplete factorial method by Carter, 1990. 53 solutions with different combinations of 5 precipitating agents, 5 buffers and 9 salts were tested. Experiments leading to immediate amorphous protein precipitate were repeated with diluted precipitating solutions.

Crystals suitable for X-ray diffraction experiments were obtained using $33 \mathrm{~mm} \mathrm{Na}$-acetate $\mathrm{pH}$ 4.6, $66 \mathrm{~mm} \mathrm{NH}_{4}$-acetate, 4-6\% (w/v) PEG 4,000 for the intact PS I monomer preparation and 33 mм Tris pH 8.5 and about $10 \%$ (w/v) PEG 4,000 for PS I $\{-\mathrm{L}\}$.

The crystals were mounted in quartz capillaries of $1 \mathrm{~mm}$ inner diameter. X-ray diffraction experiments were performed with a MAR Research Imaging Plate detector using graphite monochromatized $\mathrm{CuK} \alpha$-radiation from an ENRAFNONIUS FR571 rotating anode generator (ENRAF-NONIUS, Delft, The Netherlands) operated at $40 \mathrm{kV}, 70 \mathrm{~mA}$, focus $0.3 \times 3 \mathrm{~mm}^{2}$. In addition synchrotron $\mathrm{X}$-radiation at Lure (Laboratoire pour l'Utilisation du Rayonnement Electromagnétique, Orsay, France) was employed. The determination of unit cell dimensions and space group was supported by the auto-indexing routine of the image evaluation program DENZO (Otwinowski, 1993 ) as well as the display program XDISPLAYF (Minor, 1993), both part of the HKL-package (Xray diffraction data evaluation program, Otwinowski, 1993, and Minor, 1993).

\section{Results and Discussion}

Intact PS I monomers and PS I $\{-\mathrm{L}\}$ from $S y$ nechocystis PCC 6803 could be crystallized using polyethylene glycol with different molecular masses as precipitating agent. Table I shows the composition of those solutions used in the screening tests for crystallization conditions, which yielded crystals of one or both protein preparations. 
Table I. Results of the crystallization screening test according to Jancarik and Kim (1991). On the left, the screening test solutions are given with their respective compositions (numbered according to Jancarik and Kim (1991)). Only those solutions are described which yielded crystals of one or both of the PS I monomer preparations from Synechocystis PCC 6803, indicated by a dot in the respective column at the right. Experiments initially producing crystals were further modified to obtain larger crystals suitable for X-ray diffraction.

\begin{tabular}{|c|c|c|}
\hline Crystallization screening test-solutions & $\begin{array}{l}\text { Synechocystis } \\
\text { intact PS I monomer }\end{array}$ & $\begin{array}{l}\text { Synechocystis } \\
\text { PS I }\{-\mathrm{L}\}\end{array}$ \\
\hline $\begin{array}{l}\text { 9) } 10 \%(\mathrm{w} / \mathrm{v}) \mathrm{PEG} 4,000,66 \mathrm{~mm} \mathrm{NH}_{4} \text {-acetate, } \\
33 \mathrm{~mm} \mathrm{Na} \text {-citrate, pH } 5.6\end{array}$ & & - \\
\hline $\begin{array}{l}\text { 10) } 10 \%(\mathrm{w} / \mathrm{v}) \mathrm{PEG} 4,000,66 \mathrm{~mm} \mathrm{NH}_{4} \text {-acetate, } \\
33 \mathrm{~mm} \text { Na-acetate, } \mathrm{pH} 4.6\end{array}$ & ○ & - \\
\hline $\begin{array}{l}\text { 22) } 10 \%(\mathrm{w} / \mathrm{v}) \mathrm{PEG} 4,000,66 \mathrm{~mm} \text { Na-acetate, } \\
33 \mathrm{mM} \text { Tris/ } \mathrm{HCl}, \mathrm{pH} 8.5\end{array}$ & & - \\
\hline $\begin{array}{l}\text { 28) } 10 \%(w / v) \text { PEG 8,000, } 66 \text { mm Na-acetate, } \\
33 \text { mm Na-cacodylate, pH } 6.5\end{array}$ & & - \\
\hline 30) $10 \%(w / v)$ PEG $8,000,66 \mathrm{~mm} \mathrm{NH}_{4}$-sulphate & & - \\
\hline 31) $10 \%(\mathrm{w} / \mathrm{v})$ PEG 4,000, $66 \mathrm{~mm} \mathrm{NH}_{4}$-sulphate & & ○ \\
\hline $\begin{array}{l}\text { 37) } 8 \%(\mathrm{w} / \mathrm{v}) \text { PEG 4,000, } 100 \mathrm{~mm} \text { Na-acetate, } \\
\mathrm{pH} 4.6\end{array}$ & & ○ \\
\hline $\begin{array}{l}\text { 41) } 20 \%(\mathrm{w} / \mathrm{v}) \mathrm{PEG} 4,000,10 \% \text { (v/v) 2-propanol, } \\
100 \mathrm{~mm} \text { Hepes/NaOH, pH } 7.5\end{array}$ & - & \\
\hline 42) $10 \%(w / v)$ PEG 8,000, 25 mм K-phosphate & & O \\
\hline 43) $10 \%(w / v)$ PEG 1,500 & - & \\
\hline $\begin{array}{l}\text { 45) } 9 \%(\mathrm{w} / \mathrm{v}) \text { PEG } 8,000,100 \mathrm{~mm} \mathrm{Zn} \text {-acetate, } \\
50 \mathrm{~mm} \text { Na-cacodylate, pH } 6.5\end{array}$ & & ○ \\
\hline
\end{tabular}

The crystals grown from the PS I monomer preparations from the thermophilic Synechococcus elongatus (Jekow et al., 1995) proved all to be less fragile and more stable over several weeks than the crystals grown from PS I of the mesophilic $S y$ nechocystis PCC 6803, which was analogous to the behaviour of the respective protein solutions. On the other hand, both PS I monomers from Synechocystis PCC 6803 formed crystals easier and faster with the respective precipitating solutions than the PS I monomer preparations from Synechococcus elongatus. This might be due to the greater homogeneity of the samples from this mesophilic cyanobacterium, which could be prepared in a more gentle manner. While intact PS I could already be extracted nearly exclusively as monomers from the membrane of Synechocystis PCC 6803 using high ionic strength in the extraction buffer, PS I trimers from Synechococcus elongatus needed to be dissociated into monomers after extraction. Moreover, PS I $\{-\mathrm{L}\}$ exists in the membrane of Synechocystis PCC 6803 only in monomeric form. In case of PS I $\{-\mathrm{K},-\mathrm{L}\}$ from Synechococcus elongatus, the re- moval of the subunits $\mathrm{K}$ and $\mathrm{L}$ was performed by treatment of the PS I monomers with the zwitterionic detergent sulfobetain 12 .

Independent of the cyanobacterium used, the PS I monomer preparations deficient in subunit L yielded crystals easier and over a broader range of precipitating conditions than the intact PS I monomer preparations. This result is consistent with our proposal that the removal of this subunit from the protein complex would smoothen the irregular shape of the intact molecule and in turn facilitate crystallization (Jekow et al., 1995).

The intact PS I monomer preparation of Synechocystis PCC 6803 formed dark-green to black rodlike crystals with hexagonal cross section and reached $0.3 \times 0.3 \times 1.5 \mathrm{~mm}^{3}$ (Fig. 1a). The crystals obtained from the PS I $\{-\mathrm{L}\}$ preparation were needle shaped and grew to $0.05 \times 0.05 \times 1 \mathrm{~mm}^{3}$ (Fig. 1b). This size is suitable for X-ray diffraction experiments and could probably be enlarged by further improvement of the crystallization conditions. 

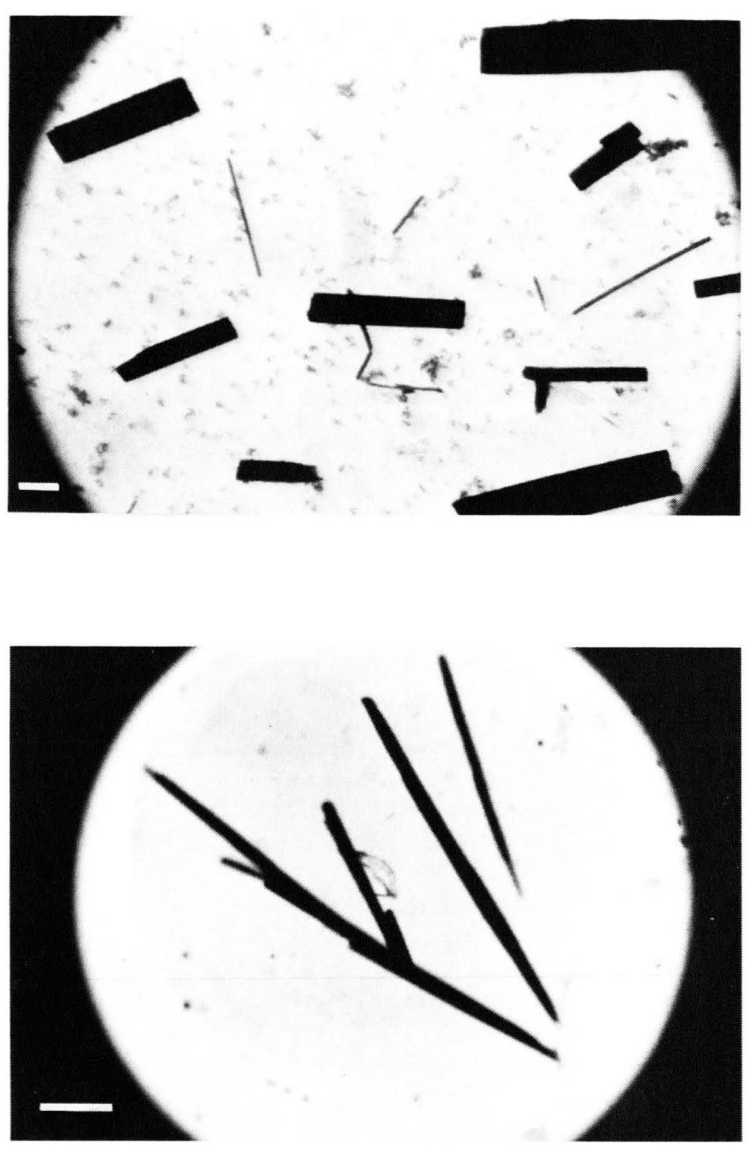

Fig. 1. Crystals (a) from intact PS I monomers from $S y$ nechocystis PCC 6803 with complete subunit composition, (b) from PS I monomers from Synechocystis PCC 6803, deficient in subunit L (PS I $\{-\mathrm{L}\}$ ), grown with PEG 4,000 using the vapour diffusion technique in the hanging drop mode. All crystals are dark-green to black depending on thickness. The bar represents $0.2 \mathrm{~mm}$.

The crystals of both preparations diffracted Xrays to a resolution of $7 \AA$ along the $c^{*}$-axis and to $12 \AA$ in the $a^{*} / b^{*}$-plane. High mosaicity exacerbated by a long $c^{*}$-axis previously prevented the characterization of the crystallographic properties of the crystals from intact PS I monomer of Synechocystis PCC 6803. By contrast, some crystals of the Synechocystis PCC 6803 PS I $\{-\mathrm{L}\}$ preparation were sufficiently well ordered to allow the space group and unit cell dimensions to be determined (Fig. 2).

The susceptibility of the Synechocystis PCC 6803 wildtype and mutant crystals to X-rays and the weak reflection intensities, both a result of small crystal size and high solvent content, pre- vented precession methods from being used in determining their space groups and unit cell lengths. Auto-indexing routines of conventional data reduction packages (DENZO (Otwinowski, 1993), Refix (Kabsch, 1993)) could not be utilized in characterizing the crystals because of the low resolution of diffraction and the extreme mosaicity of the crystals. While the latter phenomenon causes broad spot profiles and consequently poor separation of reflections, it has the advantage of providing quasi-layer photographs upon accurate crystal orientation.

Hence, an image produced with the crystal needle axis aligned parallel to the X-ray beam resulted in a quasi- $a^{*} / b^{*}$-zero-layer photograph. As this projection displayed crystallographic six-fold symmetry the lattice type was classified as hexagonal, with unit cell length $a=b=132( \pm 5) \AA$.

Orienting the crystal needle-axis to lie parallel to the rotation $\varphi$-axis (i.e. perpendicular to the $\mathrm{X}$ ray beam) resulted in an image in which the $c^{*}$ axis is projected horizontally onto the plane of the image. Highly collimated synchrotron radiation (LURE, Paris) together with a $30 \mathrm{~cm}$ MARRESEARCH Imaging Plate resulted in sufficiently

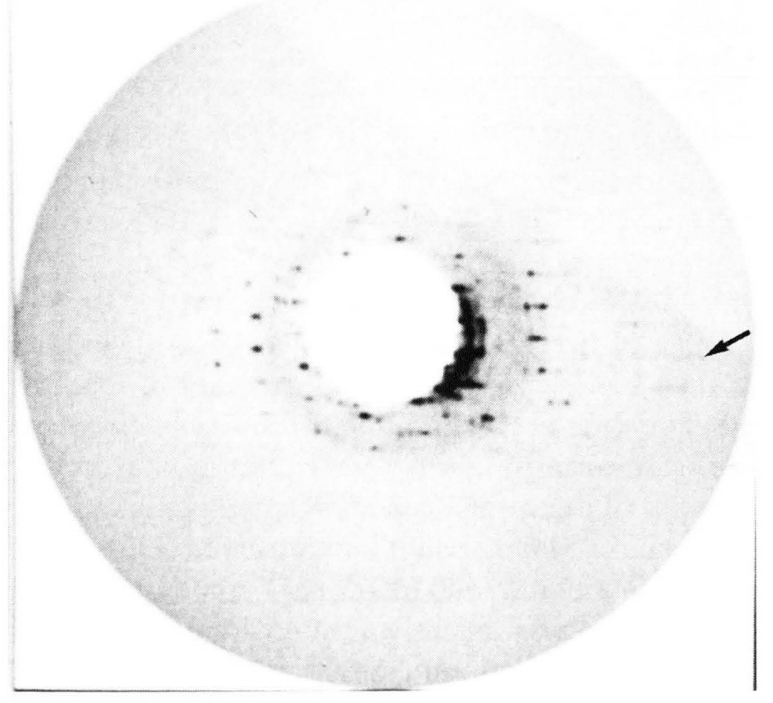

Fig. 2. X-ray diffraction pattern of a crystal from PS I $\{-\mathrm{L}\}$ monomer from Synechocystis PCC 6803. The distance between the crystal and the image plate detector was $600 \mathrm{~mm}$, the wavelength of the $\mathrm{X}$-radiation was 0.9 $\AA$ (synchrotron-radiation). The arrow indicates a maximum resolution of about $7 \AA$, the $\mathbf{c}^{*}$-axis is slightly inclined to the plane of the image and roughly horizontal. 
separated reflections to allow the systematic extinctions along the $c^{*}$-axis to be classified and the unit cell length $c$ to be determined $(c=525( \pm 10)$ $\AA)$. The extinction condition observed along the $c^{*}$-axis corresponds to $l=6 \mathrm{n}$. Thus the crystals space group is either $\mathrm{P}_{1}$ or the enantiomorphic $\mathrm{P}_{5}$.

Having identified the crystal symmetry and unit cell lengths it was possible to manually derive and refine the crystal orientation (Mosflm (Kabsch, 1993), DENZO (Otwinowski, 1993) together with associated graphic display software (Leslie, 1990)) for images of randomly-oriented crystals, further corroborating the space group assignment.

The results presented in this article indicate a special role of subunit $\mathrm{L}$ in hindering crystal for-

Almog O., Shoham G., Michaeli D. and Nechushtai R. (1991), Monomeric and trimeric forms of photosystem I reaction center of Mastigocladus laminosus: Crystallization and preliminary characterization. Proc. Natl. Acad. Sci. USA 88, 5312-5316.

Carter C.W. jr. (1990), Efficient factorial designs and the analysis of macromolecular grystal growth conditions. In Methods: Protein and Nucleic Acid Crystallization (ed. Carter, C.W. jr.). Acad. Press, USA, pp. 12-24.

Chitnis V.P. and Chitnis P.R. (1993), PsaL subunit is required for the formation of photosystem I trimers in the cyanobacterium Synechocystis sp. PCC 6803. FEBS Lett. 336, 330-334.

Chitnis V.P., Xu Q., Yu L., Golbeck J.H., Nakamoto H., Xie D.-L. and Chitnis P.R. (1993), Targeted inactivation of the gene psaL encoding a subunit of photosystem I of the cyanobacterium Synechocystis sp. PCC 6803. J. Biol. Chem. 268, 11678-11684.

Ford R.C. and Holzenburg A. (1988), Investigation of the structure of trimeric and monomeric photosystem I reaction center complexes. EMBO Journal 7, 2287-2293.

Golbeck J.H. (1993), Shared thematic elements in photochemical reaction centers. Proc. Natl. Acad. Sci. USA 90, $1642-1646$.

Jancarik K. and Kim S.-H. (1991), Sparse matrix sampling: a screen method for crystallization of proteins. J. Appl. Cryst. 24, 409-411.

Jekow P., Fromme P., Witt H.T. and Saenger W. (1995), Photosystem I from Synechococcus elongatus: Preparation and crystallization of monomers with varying subunit compositions. Biochim. Biophys. Acta 1229, $115-120$.

Kabsch W. (1993), Automatic processing of rotation diffraction data from crystals of initially unknown symmetry and cell constants. J. Appl. Cryst. 24, 795-800.

Krauß N., Hinrichs W., Witt I., Fromme P., Pritzkow W., Dauter Z., Betzel C., Wilson K.S., Witt H.T. and mation, and show the importance of the membrane embedded protein subunits in determining the crystallization behaviour of the whole protein complex. They also show the potential of using specifically designed deletion mutants of membrane proteins for the systematic improvement of crystal structure data.

\section{Acknowledgments}

This work was supported by the Deutsche Forschungsgemeinschaft through its Sonderforschungsbereich 312 and by Fonds der Chemischen Industrie (W.S.).

Saenger W. (1993), Three-dimensional structure of system I of photosynthesis at $6 \AA$ resolution, Nature 361, 326-371.

Kruip J., Boekema E.J., Bald D. and Rögner M. (1993), Evidence for the existence of trimeric and monomeric photosystem I complexes from thylakoid membranes from cyanobacteria. Photosynth. Res. 40, 279-285.

Kruip J., Boekema E.J., Bald D., Boonsta A. and Rögner M. (1993), Isolation and structural chracterization of monomeric and trimeric photosystem I complexes $\left(\mathrm{P} 700, \mathrm{~F}_{\mathrm{A}} / \mathrm{F}_{\mathrm{B}}\right.$ and $\left.\mathrm{P} 700, \mathrm{~F}_{\mathrm{X}}\right)$ from the cyanobacterium Synechocystis PCC 6803. J. Biol.Chem. 268, 2335323360.

Leslie A.G.W. (1990), The CCP4 Suite: Computer program for protein crystallography, Crystallographic Computing. Oxford University Press, UK.

Minor W. (1993), ,XDISPLAYF Program“. Purdue University, UK.

Mühlenhoff U., Haehnel W., Witt H.T. and Herrmann R.G. (1993), Genes encoding eleven subunits of photosystem I from the thermophilic cyanobacterium $S y$ nechococcus sp. Gene 127, 71-78.

Otwinowski Z., Oscillation Data Reduction Program. In Proceedings of the CCP4 Study Weekend: „Data Collection and Processing“, 29-30 January 1993, (compiled by Sawyer, L., Isaacs, N. and Bailey, S.) SERC Daresbury Laboratory, England, pp. 56-62.

Rögner M., Mühlenhoff U., Boekema E.J. and Witt H.T. (1990), Mono-, di- and trimeric PS I reaction center complexes isolated from the thermophilic cyanobacterium Synechococcus sp.: size, shape and activity. Biochim. Biophys. Acta 1015, 415-424.

Rögner M., Nixon P.J. and Diner B.A. (1990), Purification and characterization of photosystem I and photosystem II core complexes from wild-type and phycocyanin-deficient strains of cyanobacterium Synechocystis PCC 6803. J. Biol. Chem. 265, 61896196. 